\title{
Density Functional Theory Study of Methyl lodide Adsorption and Dissociation on Clean and K-Promoted $\boldsymbol{\beta}$ - $\mathrm{Mo}_{2} \mathrm{C}$ Surfaces
}

\author{
M. E. Pronsato, ${ }^{\dagger}$ C. Pistonesi, ${ }^{\dagger}$ A. Juan,,$^{*+}$ A. P. Farkas, ${ }^{\ddagger}$ L. Bugyi, ${ }^{\ddagger}$ and F. Solymosi ${ }^{\ddagger}$ \\ ${ }^{\dagger}$ Departamento de Física \& IFISUR, Universidad Nacional del Sur-CONICET, Avda. Alem 1253, 8000 Bahía Blanca, Argentina \\ ${ }^{\ddagger}$ Reaction Kinetics Research Group, Chemical Research Centre of the Hungarian Academy of Sciences, University of Szeged, \\ P.O. BOX 168, H-6701 Szeged, Hungary
}

ABSTRACT: We have studied the effect of $\mathrm{K}$ on the adsorption and dis sociation of methyl iodide on the $\beta-\mathrm{Mo}_{2} \mathrm{C}(001)$ surface using density functional theory calculations, and the results were compared with experimental data. The most favorable sites for methyl iodide adsorption are 3-fold sites on both clean and K-promoted surface. The changes in the work function fit our model as the molecule withdraws charge from the surface. The $\mathrm{C}-\mathrm{I}$ bond weakens when the molecule adsorbs on the surface, and this effect is more noticeable on the K-promoted surface. The
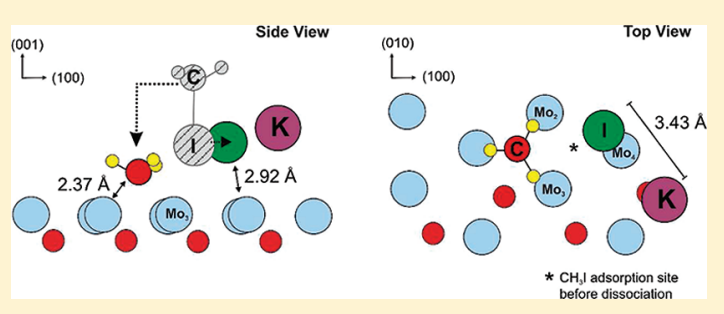
dissociation to an I adsorbed atom and a methyl group adsorbed is energetically favorable for both surfaces, but there is a lower activation barrier on the K-doped surface.

\section{INTRODUCTION}

The adsorption of the methyl group on metal surfaces is of interest from a catalytic and theoretical point of view. A methyl intermediate is expected to form during Fischer-Tropsch synthesis and catalytic conversion of methane. Since nickel is a catalyst for commercial steam reforming of methane, a lot of experimental and theoretical study is focused on the investigation of methyl groups on nickel surfaces; see, for example, ref 1 . DFT calculations addressed the effect of coadsorbed iodine ${ }^{2}$ and the decomposition pathway of $\mathrm{CH}$ fragments ${ }^{3}$ as well. Taking into account that the activation of the $\mathrm{C}-\mathrm{H}$ bond in methane requires high energy, while the $\mathrm{C}-\mathrm{I}$ bond breaks rather easily, adsorbed methyl iodide has been used as a precursor for generation of methyl groups by thermal activation or photolysis on different metal surfaces. There is a good deal of information about the decomposition process deduced from experiments, ${ }^{4,5}$ but theoretical works are scarcer. It was found that the interaction of $\mathrm{CH}_{3} \mathrm{I}$ with the coinage metals is weak leaving intact the majority of thermally desorbed molecules; ${ }^{4}$ on the other hand, on active metals like molybdenum the molecule decomposed at about $200 \mathrm{~K}^{6}$ It is advantageous to characterize the surface interaction of molecules through simulation and experimental work at the same time, and an example for this is a combined DFT and STM study of $\mathrm{CH}_{3} \mathrm{I}$ decomposition on the $\mathrm{Al}(111)$ plane. ${ }^{7}$

It is of great demand to replace the expensive and rare platinum metals with cheap and effective catalysts. It is known that molybdenum carbide has catalytic activity similar to platinum metals, exhibiting also a higher sulfur resistance. ${ }^{8}$ At the same time, on molybdenum carbides, new reaction routes were also experienced as compared to platinum metal catalysts. An example for this is the aromatization reaction of methane on $\mathrm{Mo}_{2} \mathrm{C}$ supported by ZSM- $5,{ }^{9}$ which is of great practical importance. One of the elementary reaction steps of aromatization is the formation of $\mathrm{C}_{2}$ intermediate that is followed by trimerization. The coupling reaction of methyl groups generated from decomposition of methyl iodide on molybdenum carbide model catalysts was addressed under UHV conditions, and the formation of ethene could be detected. ${ }^{10}$ DFT calculations on a $\beta-\mathrm{Mo}_{2} \mathrm{C}(001)$ slab revealed the energetics of methane reforming and coupling reactions. $^{11}$

It is well documented that alkali metal additives may have a substantial promotional effect on different metals like iron and platinum in heterogeneous catalytic reactions like ammonia and Fischer-Tropsch synthesis. ${ }^{12,13}$ Adsorption and bonding of potassium on $\mathrm{Mo}_{2} \mathrm{C}^{1}$ exhibit features similar to those determined for alkali metals on single-crystal surfaces. ${ }^{12}$ Work function (WF) changes following potassium deposition on the $\mathrm{Mo}_{2} \mathrm{C} / \mathrm{Mo}(100)$ surface were determined to establish the direction of charge transfer. ${ }^{1} \mathrm{WF}$ of $\mathrm{Mo}_{2} \mathrm{C} / \mathrm{Mo}(100)$ steeply decreases with $\mathrm{K}$ coverage up to $\Theta_{\mathrm{K}} \sim 1.0(\Delta \Phi=-3.3 \mathrm{eV})$, suggesting a considerable charge-transfer from potassium to the surface at lower coverages. Further K deposition leads to a slight increase in WF, corresponding to a gradual neutralization at and above one monolayer. Accordingly, the potassium adlayer is mainly ionic at low and metallic at high coverages. At low $\mathrm{K}$ coverage, potassium is strongly bonded to the surface as reflected by a high desorption peak temperature, $T_{\mathrm{p}}=850 \mathrm{~K}$. This peak shifted to $525 \mathrm{~K}$ for monolayer and to $325 \mathrm{~K}$ for multilayer coverage, indicating a much weaker bond at higher coverages.

The promotional effect of alkali metals can be related to indirect through-metal and to direct alkali-adsorbate interactions,

Received: November 1, 2010

Revised: January 3, 2011

Published: January 25, 2011 
resulting in ionic and covalent bond formation between the alkali metal and adsorbate. The electron donation to the antibonding orbitals of simple molecules, like $\mathrm{CO}, \mathrm{NO}$, etc., leads to bond weakening between the constituent atoms, occasionally causing the rupture of the bond. Promotion of weakening and scission of chemical bonds in reactant molecules may enhance catalytic performance. It is of great practical importance that alkali additives can change the reaction route of surface hydrocarbon fragment intermediates formed during the Fischer-Tropsch synthesis. ${ }^{12}$ For this reason, we have addressed the effect of an alkali metal, potassium, on the reaction path of the simple alkyl group, $\mathrm{CH}_{3}$, on the $\mathrm{Mo}_{2} \mathrm{C}$ surface, which behaves similarly to platinum metals in many respects. ${ }^{14}$ The effect of potassium on the reaction path of the methyl iodide molecule on molybdenum carbide was that the surface concentration of methyl groups could be remarkably enhanced, and their decomposition to surface carbon was suppressed, allowing higher conversion toward coupling products. ${ }^{15}$ Note that on molybdenum carbide the reactivity of other alkyl iodides ${ }^{15-17}$ toward adsorbed potassium was similar to that of methyl iodide, and potassium was also reactive with other alkyl halides on other surfaces as well, for example, with $\mathrm{CH}_{3} \mathrm{Cl}$ on $\mathrm{Pd}(100)^{18}$ and $\mathrm{Rh}(111)^{19}$ crystal planes. The explanation for the reactivity in simple terms is that the electrons originating from $\mathrm{K} 4 \mathrm{~s}$ orbital are easily donated to halogen atoms $(\mathrm{X})$, resulting in the formation of a strong $\mathrm{K}+$ $\mathrm{X}$ - ionic bond, which facilitates the rupture of the $\mathrm{C}-\mathrm{X}$ bond. This mechanism suggests that the behavior of other alkali metals with other alkyl halides on different transition metal surfaces is expectably very similar. In the case of metal single crystals it was observed that not only potassium influences desorption of adsorbed species but also bonding of potassium is also affected by the coadsorbed compounds, indicating a strong interaction between them. ${ }^{20}$ This phenomenon also occurred on the $\mathrm{Mo}_{2} \mathrm{C}$ surface, particularly at high $\mathrm{K}$ coverage.

To expand our understanding on the effect of alkali metal additives on the generation of methyl groups, in the present work the adsorption of the methyl iodide molecule and its dissociation into iodine and methyl groups is investigated on a clean and potassium-promoted $\mathrm{Mo}_{2} \mathrm{C}$ surface using DFT calculations and work function measurements.

\section{COMPUTATIONAL METHOD AND MODEL}

DFT calculations were performed with the Vienna Ab-Initio Simulation Package (VASP). ${ }^{21}$ Potentials within the projectoraugmented wave method (PAW $)^{22}$ and the generalized gradient approximation (GGA) with the Perdew-Burke-Ernzerhof functional $(\mathrm{PBE})^{23,24}$ were used. The calculations were performed without spin polarization.

Geometry optimizations were performed by minimizing the total energy of the system using a conjugated-gradient algorithm to relax the ions. ${ }^{25} \mathrm{~A} 5 \times 5 \times 5$ Monkhorst-Pack k-point grid for sampling the Brillouin zone was considered. Larger sets of k-points were also considered $(6 \times 6 \times 6$ and $7 \times 7 \times 7)$, finding differences in the configuration energy of about $0.02 \%$. The electronic charges on atoms were computed using the Bader analysis. ${ }^{26}$

The $\beta-\mathrm{Mo}_{2} \mathrm{C}$ phase has an orthorhombic crystal structure with Mo atoms slightly distorted from their positions in close-packed planes and carbon atoms occupying one-half of the octahedral interstitial sites (many literature reports refer to the (0001) plane as a closest-packed surface). The corresponding unit cell is composed by eight molybdenum atoms and four carbon atoms. The surface was modeled by four layers of slabs separated by a vacuum using the DFT lattice parameters previously obtained from bulk optimization. During optimization, the first two layers were allowed to fully relax, and a set of $3 \times 3 \times 1$ Monkhorst - Pack k-points was used. Besides, for adsorption calculations the adsorbed species and the first two surface layers were allowed to relax. In all cases, the cutoff energy used was $750 \mathrm{eV}$.

The adsorption energy was computed by subtracting the energies of the gas-phase species and the surface from the energy of the adsorbed system as follows

$$
E_{\text {ads }}=E(\text { adsorbate } / \text { slab })-E(\text { adsorbate })-E(\text { slab })
$$

With this definition, a negative adsorption energy corresponds to a stable adsorption on the surface.

For a qualitative study on bonding, the concept of overlap population (OP) as implemented in the YAeHMOP code was employed. ${ }^{27}$ For this, the optimized geometries previously obtained from DFT were used. A similar procedure was implemented by Papoian et al. ${ }^{28}$

\section{RESULTS}

3.1. Surface Characterization. The calculated DFT lattice parameters for the bulk $\beta-\mathrm{Mo}_{2} \mathrm{C}$ are $a=5.273 \AA, b=6.029 \AA$, and $c=4.775 \AA$, which are very close to the experimental values $(a=$ $5.195 \AA, b=6.022 \AA, c=4.725 \AA) .{ }^{29}$ Our computed value for the bulk modulus was $307.1 \mathrm{GPa}$, in excellent agreement with the experimental data of $307 \mathrm{GPa} .{ }^{30}$ Each of the lattice parameters was overestimated by $1-2 \%$. The bulk $\beta-\mathrm{Mo}_{2} \mathrm{C}$ lattice parameters were determined for later use in investigations of supercell properties described in the next section.

The structure of the $\beta-\mathrm{Mo}_{2} \mathrm{C}(001)$ surface includes a series of alternating $\mathrm{Mo}$ and $\mathrm{C}$ layers. We modeled the surface with a slab of four-layer thickness (two layers of Mo atoms and two layers of C atoms), and each slab has two formula unit cells width. The vacuum spacing between two repeated slabs was $11.8 \AA$ to ensure no significant interaction between the slabs. During optimization, surface Mo and subsurface C layers were allowed to fully relax, while the other two layers were kept frozen at their bulk lattice parameters. The resulting interlayer distances become shorter than those in the bulk. Previous theoretical studies on this surface conclude that the metal-terminated carbide surface adsorbs $\mathrm{H}$ and methanol more strongly than the $\mathrm{C}$-terminated surface. $^{31-33}$

A low potassium coverage was added on the surface on 3-fold positions. Although similar adsorption energies were obtained at different adsorption sites, a preferential tricoordinated model at low coverage was obtained on similar systems. ${ }^{34,35}$ According to the experimental procedure in ref $15, \mathrm{~K}$ was added neutral prior to $\mathrm{CH}_{3} \mathrm{I}$ adsorption. For this system, surface Mo and subsurface $\mathrm{C}$ layers, and also the $\mathrm{K}$ atom, were allowed to fully relax during optimization.

We considered a $\mathrm{K}$ coverage of $1 / 8$, defined as the ratio between the number of adsorbed $\mathrm{K}$ atoms and surface $\mathrm{Mo}$ atoms. The optimized $\mathrm{K}-$ Mo distance was $3.6 \AA$ (see Figure 1). A similar K-metal distance of $3.5 \AA$ was obtained by Calzado et al. ${ }^{34}$ for $\mathrm{K}$ adsorption on the tricoordinated $\mathrm{TiO}_{2}(110)$ surface.

Regarding the electronic structure, surface Mo atoms showed an increase in the electron density $\left(0.14 \mathrm{e}^{-}\right.$for the first neighbor to the $\mathrm{K}$ atom), while $\mathrm{K}$ was positively charged. The Mo d 


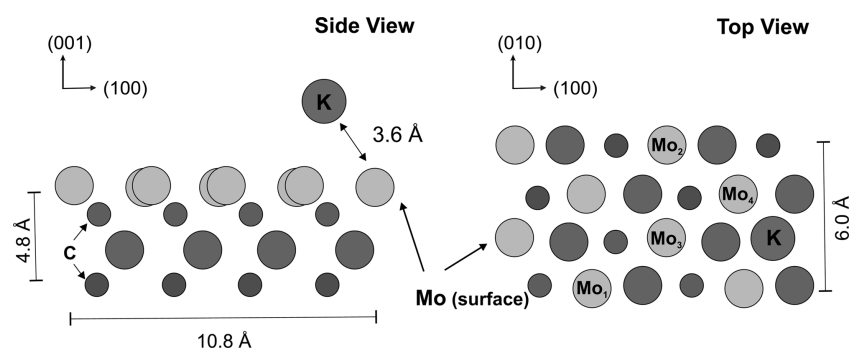

Figure 1. Two views of the potassium-promoted $\mathrm{Mo}_{2} \mathrm{C}$ slab.

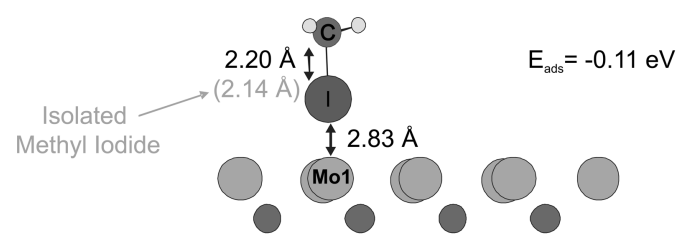

(a) Methyl iodide on Mo top

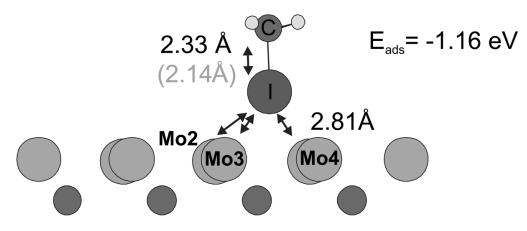

(b) Methyl iodide on a three fold site

Figure 2. Surface structure of methyl iodide adsorption on the $\mathrm{Mo}_{2} \mathrm{C}$ surface on a Mo top site (a) and on a 3-fold site (b). For clarity, not all the surface is shown, and only the first two layers are included. The parentheses indicate $\mathrm{C}-\mathrm{I}$ distances before adsorption.

population increases from 3.28 to 3.41 showing the influence of K. Similar results were obtained by Kotarba et al. ${ }^{36}$

3.2. Methyl lodide Adsorption on the Clean Mo-Terminated $\boldsymbol{\beta}-\mathrm{Mo}_{2} \mathrm{C}$ Surface. Taking into account previous results for adsorption on metal surfaces ${ }^{20,37,38}$ and for other similar alkyl iodides, ${ }^{16,17,39-43}$ we considered the adsorption of the molecule via iodine on a Mo-terminated surface. Two possible sites for $\mathrm{CH}_{3} \mathrm{I}$ adsorption were investigated, a Mo top site and a 3-fold Mo site. The adsorbate and the first two layers of the slab were fully relaxed.

For both cases, the final adsorption geometry presents the molecule bonded perpendicularly to the surface as shown in Figure 2 .

For the top site, the $\mathrm{I}-\mathrm{Mo}$ bond distance is $2.83 \AA$, while the $\mathrm{C}-\mathrm{I}$ (from $\mathrm{CH}_{3} \mathrm{I}$ ) distance increases $3 \%$ with respect to the isolated molecule. The calculated adsorption energy is $-0.11 \mathrm{eV}$. In the case of the 3-fold site, I-Mo distances range between 2.79 and $2.83 \AA$ with the molecule closer to the surface, with a perpendicular distance of $2.20 \AA$. In this case, the $\mathrm{C}$-I bond increases even more (9\%) upon adsorption, and the adsorption energy is $-1.16 \mathrm{eV}$. This result represents a higher binding energy than was established by TPD for molecular $\mathrm{CH}_{3} \mathrm{I}$ desorption, ${ }^{15}$ but it must be taken into account that during annealing the most strongly bonded molecules follow a reaction channel ending in decomposition instead of desorption. The above finding means that even though both (top and 3-fold) are possible $\mathrm{CH}_{3} \mathrm{I}$ adsorption sites the 3 -fold site is the most favorable. Mo atoms and subsurface $\mathrm{C}$ atoms of the carbide surface do not present noticeable location shift when compared with the clean $\mathrm{Mo}_{2} \mathrm{C}$ surface. The molecular distances of isolated and adsorbed methyl iodide for each adsorption site and the corresponding adsorption energies are presented in Table 1.

Table 2 shows the computed charges for the clean surface and the $\mathrm{CH}_{3} \mathrm{I}$ molecule. The surface transfers charge to the molecule, making it negative. When $\mathrm{CH}_{3} \mathrm{I}$ is adsorbed on top (on Mol) there is a small decrease in the electronic charge of the surface Mo atoms close to the $\mathrm{CH}_{3} \mathrm{I}$ (an increase in the positive charge means a decrease in the electronic charge). The first row in Table 2 shows that the electronic charge on Mol changes from 0.535 to 0.570 , decreasing $0.035 \mathrm{e}^{-}$after adsorption. When comparing the adsorbed species with an isolated $\mathrm{CH}_{3} \mathrm{I}$ molecule in vacuum, the $\mathrm{H}$ and $\mathrm{C}$ atoms lose some of their orbital occupation, while the I atom gains electron density changing its charge from +0.119 to -0.020 . As a result, the total charge of the adsorbed $\mathrm{CH}_{3} \mathrm{I}$ becomes $-0.031 \mathrm{e}^{-}$.

When $\mathrm{CH}_{3} \mathrm{I}$ is adsorbed on a 3 -fold site (formed by Mo2, Mo3, and Mo4), its electron density increases mainly from three (instead of one) Mo atoms. The molecule becomes more negatively charged than when it is adsorbed on top. Iodine is the most affected part of the molecule, getting an additional $0.151 \mathrm{e}^{-}$. In this case, the net charge of the adsorbed molecule becomes $-0.247 \mathrm{e}^{-}$, which is larger than the charge for the adsorbed molecule on top.

3.3. Methyl lodide Adsorption on the K-Promoted MoTerminated $\boldsymbol{\beta}-\mathrm{Mo}_{2} \mathrm{C}$ Surface. The adsorption of the methyl iodide molecule was also investigated on the potassium-promoted $\mathrm{Mo}_{2} \mathrm{C}$ surface. The adsorbate, the first two layers of the slab, and the $\mathrm{K}$ adlayer were fully relaxed.

As mentioned before, two possible sites for $\mathrm{CH}_{3} \mathrm{I}$ adsorption were investigated: the $\mathrm{K}$ top site and a 3-fold site. Different 3-fold sites were considered, a 3-fold site close to the $\mathrm{K}$ atom being the most energetically favorable (this is the 3 -fold site formed by $\mathrm{Mo} 2, \mathrm{Mo} 3$, and $\mathrm{Mo} 4$ atoms). The adsorption energy of $\mathrm{CH}_{3} \mathrm{I}$ on the $\mathrm{K}$ top site is $-0.17 \mathrm{eV}$, while that on the closest 3-fold site is $-0.94 \mathrm{eV}$. This means that the 3 -fold is the most favorable adsorption site also on the K-promoted surface.

For the $\mathrm{K}$ top site the $\mathrm{I}-\mathrm{K}$ distance is $3.13 \AA$, and the $\mathrm{CH}_{3} \mathrm{I}$ molecule is far from the surface. As a result, its geometry is similar to that of the isolated molecule (see Table 1 and Figure 3).

On the other hand, for the 3-fold site the $\mathrm{C}-\mathrm{I}$ distance increases $21 \%$ upon adsorption. The stretch is even larger than the case of adsorption on the clean surface. The I-Mo distances range between 2.84 and $2.93 \AA$, so the molecule is pushed away from the surface compared to the clean system.

When $\mathrm{CH}_{3} \mathrm{I}$ is adsorbed on the $\mathrm{K}$ top site, there is less charge transfer than in the previous cases resulting in a net charge of $-0.018 \mathrm{e}^{-}$.

When $\mathrm{CH}_{3} \mathrm{I}$ is adsorbed on a 3 -fold site closer to $\mathrm{K}$, the charge transfer from the surface to the molecule is much larger than in the case on the clean surface. Both $\mathrm{H}$ and $\mathrm{C}$ atoms reduce their charge, while there is an important increase on the iodine electron density. As a result the net charge of the molecule is $-0.516 \mathrm{e}^{-}$ instead of $-0.247 \mathrm{e}^{-}$on a 3 -fold site on the clean surface.

To establish the charge transfer between the molybdenum carbide surface and the methyl iodide molecule in the absence and presence of potassium adatoms $\left(\Theta_{\mathrm{K}}=0.28\right)$, work function (WF) measurements were carried out. WF data were collected with the electron gun and analyzer used for Auger Electron Spectroscopy in the way described previously, ${ }^{44}$ based on recording the shift in the secondary electron energy threshold. Having a large dipole moment, the adsorption and surface rearrangement of 
Table 1. Calculated Geometric Parameters for Isolated and Adsorbed Methyl Iodide on Clean and on K-Promoted Surface ${ }^{a}$

\begin{tabular}{|c|c|c|c|c|c|c|}
\hline & & \multirow[b]{2}{*}{ isolated } & \multicolumn{2}{|c|}{ clean $\mathrm{Mo}_{2} \mathrm{C}$} & \multicolumn{2}{|c|}{$\mathrm{K}-\mathrm{Mo}_{2} \mathrm{C}$} \\
\hline & & & Mo top site & Mo 3 fold site & $\mathrm{K}$ top site & Mo 3-fold site \\
\hline \multirow{6}{*}{$\begin{array}{l}E_{\text {ads }}(\mathrm{eV}) \\
\text { distance }(\AA)\end{array}$} & & - & -0.11 & -1.16 & -0.17 & -0.94 \\
\hline & $\mathrm{C}-\mathrm{H}$ & 1.09 & 1.09 & 1.09 & 1.09 & 1.10 \\
\hline & $\mathrm{C}-\mathrm{I}$ & 2.14 & 2.20 & 2.33 & 2.14 & 2.58 \\
\hline & $\mathrm{I}-\mathrm{Mo}$ & - & 2.83 & $2.79-2.83$ & - & $2.84-2.92$ \\
\hline & $\mathrm{I}-\mathrm{K}$ & - & - & - & 3.13 & 3.45 \\
\hline & $\mathrm{K}-\mathrm{Mo}$ & - & - & - & $3.49-3.53^{b}$ & $3.58-3.67^{b}$ \\
\hline
\end{tabular}

Table 2. Net Charges for Specific Atoms on a Clean $\mathrm{Mo}_{2} \mathrm{C}$ Surface, on Isolated $\mathrm{CH}_{3} \mathrm{I}$, and after Adsorption

\begin{tabular}{|c|c|c|c|c|}
\hline \multirow[b]{2}{*}{ charge } & \multicolumn{2}{|c|}{ isolated } & \multicolumn{2}{|c|}{ adsorbed methyl iodide } \\
\hline & surface & methyl iodide & on Mo top & on Mo 3-fold \\
\hline Mol & 0.535 & - & 0.570 & 0.540 \\
\hline Mo2 & 0.225 & - & 0.246 & 0.320 \\
\hline Mo3 & 0.538 & - & 0.561 & 0.646 \\
\hline Mo4 & 0.226 & - & 0.218 & 0.329 \\
\hline $\mathrm{H}$ (avg) & - & 0.040 & 0.061 & 0.039 \\
\hline $\mathrm{C}$ & - & -0.239 & -0.194 & -0.193 \\
\hline I & - & 0.119 & -0.020 & -0.171 \\
\hline$q\left(\mathrm{CH}_{3} \mathrm{I}\right)^{a}$ & & 0.000 & -0.031 & -0.247 \\
\hline
\end{tabular}

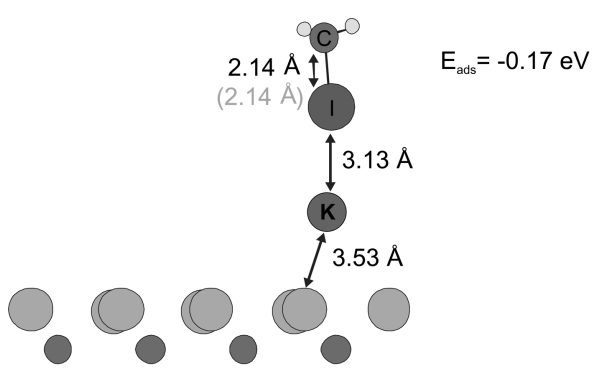

(a) Methyl iodide on $\mathrm{K}$ top

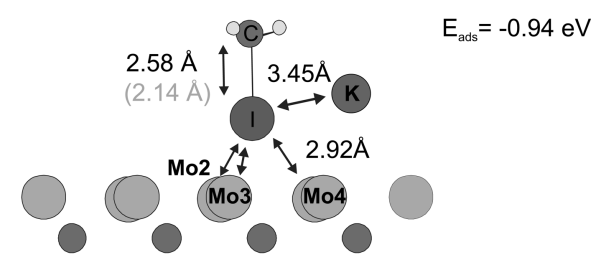

(b) Methyl iodide on a three fold site

Figure 3. Surface structure of methyl iodide adsorption on the $\mathrm{K}-\mathrm{Mo}_{2} \mathrm{C}$ surface on a $\mathrm{K}$ top site (a) and on a 3 -fold site (b). For clarity only a section of the surface is shown. The parentheses indicate $\mathrm{C}-\mathrm{I}$ distances before adsorption.

molecular $\mathrm{CH}_{3} \mathrm{I}$ is expected to be followed easily by WF measurements. ${ }^{45}$ In Figure 4 the work function changes of the above surfaces are plotted as a function of $\mathrm{CH}_{3} \mathrm{I}$ exposure performed at $100 \mathrm{~K}$. On both surfaces, a nearly linear change in WF was found up to $\sim 4 \mathrm{~L}$ exposure. It was observed previously ${ }^{15}$

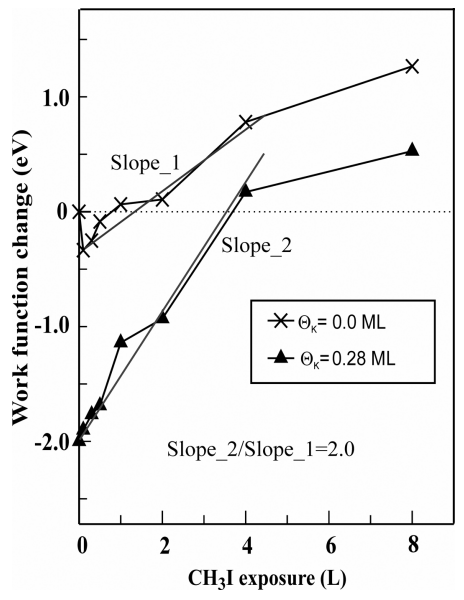

Figure 4. Changes in the work function (WF) of K-free and K-dosed $\left(\Theta_{\mathrm{K}}=0.28 \mathrm{ML}\right) \mathrm{Mo}_{2} \mathrm{C} / \mathrm{Mo}(100)$ surfaces as a function of $\mathrm{CH}_{3} \mathrm{I}$ exposure.

that $0.35 \mathrm{ML} \mathrm{K}$ promoted the decomposition of $\mathrm{CH}_{3} \mathrm{I}$ at $115 \mathrm{~K}$ only about to $5 \%$ following $4 \mathrm{~L}$ exposure. Accordingly, the WF values measured as a result of $\mathrm{CH}_{3} \mathrm{I}$ uptake (Figure 4) reflect the charge transfer to the intact molecule up to $4 \mathrm{~L}$ exposure, except those measured at the lowest exposures. The extent of chargetransfer in the presence and in the absence of potassium can be estimated from WF measurements. The slope of lines fitted to the WF data points indicates that in the presence of $\mathrm{K}$ the surface dipole moment is enhanced by a factor of 2.0, which is in excellent agreement with the calculated total charge transfer to the molecule bonded in 3-fold hollow sites (Table 2 and Table 3). The above argument involves similar surface concentration for methyl iodide at a given exposure on the K-free and K-dosed surfaces, which was really observed by XPS measurements. ${ }^{15}$

Table 4 shows the computed overlap population, for bonds on isolated and adsorbed methyl iodide. We can see in all cases that the OP value for the $\mathrm{C}-\mathrm{I}$ bond reduces when methyl iodide is adsorbed, resulting in the weakening of the $\mathrm{C}-\mathrm{I}$ bond before adsorption.

On the clean surface, this reduction is $9 \%$ for adsorption on top and $15 \%$ for adsorption on a 3 -fold site. While on the K-promoted surface, the reduction is only $1 \%$ when methyl iodide is adsorbed on $\mathrm{K}$ top but is $38 \%$ on a 3-fold Mo site near $\mathrm{K}$. We can conclude that the $\mathrm{C}-\mathrm{I}$ bond weakening is higher on the 3-fold Mo site near K. Such bond weakening is in agreement with the elongation of the $\mathrm{C}-\mathrm{I}$ distance.

We have calculated the atom-projected density of states (PDOS) by projection of the one-electron states onto spherical 
Table 3. Net Charges for Specific Atoms on the $\mathrm{K}-\mathrm{Mo}_{2} \mathrm{C}$ Surface, on Isolated $\mathrm{CH}_{3} \mathrm{I}$, and after Adsorption

\begin{tabular}{lccccc} 
& \multicolumn{2}{c}{ isolated } & & \multicolumn{2}{c}{ adsorbed methyl iodide } \\
\cline { 2 - 3 } \cline { 5 - 6 } charge & surface & methyl iodide & & on K top & on Mo 3-fold \\
Mo2 & 0.213 & - & & 0.218 & 0.323 \\
Mo3 & 0.488 & - & & 0.504 & 0.639 \\
Mo4 & 0.089 & - & & 0.102 & 0.261 \\
K & 0.774 & - & & 0.764 & 0.785 \\
H (avg) & - & 0.040 & & 0.096 & 0.015 \\
C & - & -0.239 & & -0.248 & -0.232 \\
I & - & 0.119 & & -0.058 & -0.329 \\
$q\left(\mathrm{CH}_{3} \mathrm{I}\right)^{a}$ & & 0.000 & & -0.018 & -0.516 \\
${ }^{a}$ Net charge of $\mathrm{CH}_{3} \mathrm{I}$ molecule & & \\
\hline
\end{tabular}

Table 4. Overlap Population (OP) for Selected Bonds on Isolated and Adsorbed Methyl Iodide

\begin{tabular}{cccccccc} 
& & \multicolumn{2}{c}{ on clean $\mathrm{Mo}_{2} \mathrm{C}$} & & \multicolumn{2}{c}{ on $\mathrm{K}-\mathrm{Mo}_{2} \mathrm{C}$} \\
\cline { 3 - 5 } \cline { 6 - 7 } OP & isolated & on Mo top & on Mo 3-fold & & on $\mathrm{K}$ top & on Mo 3-fold \\
$\mathrm{C}-\mathrm{H}$ & 0.856 & 0.859 & 0.855 & & 0.860 & 0.866 \\
$\mathrm{C}-\mathrm{I}$ & 0.605 & 0.553 & 0.512 & & 0.597 & 0.378 \\
$\mathrm{I}-\mathrm{Mo}$ & - & 0.441 & $0.453-0.472$ & & - & $0.308-0.382$ \\
$\mathrm{I}-\mathrm{K}$ & - & - & - & 0.316 & 0.086 \\
\hline
\end{tabular}

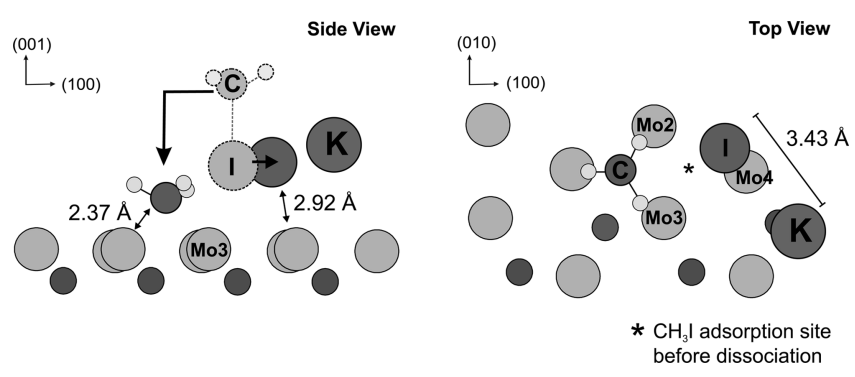

Figure 5. Dissociation of $\mathrm{CH}_{3} \mathrm{I}$ on adsorbed $\mathrm{CH}_{3}$ and $\mathrm{I}$. $\mathrm{CH}_{3} \mathrm{I}$ before dissociation is represented in gray. On the side view, the dotted lines represent the suggested reaction pathway. On the top view, the adsorption site before dissociation is indicated.

harmonic atomic orbitals centered on atomic sites (Figure 7). PDOS on surface Mo, C, and $\mathrm{K}$ atoms is presented in Figure 7a. The peak around $-12.5 \mathrm{eV}$ can be attributed to interactions between $\mathrm{C}$ s-orbitals with Mo orbitals, while the band between -6 and $2 \mathrm{eV}$ is mainly the Mo d-band interacting with the $\mathrm{C}$ p-band on its lower-energy part (between -6 and $-3 \mathrm{eV}$ ). The peak at $-15 \mathrm{eV}$ correponds to the $\mathrm{K}$ p-orbitals. There is also a strong peak at $-35 \mathrm{eV}$ from Mo p-orbitals and at $-32.5 \mathrm{eV}$ from $\mathrm{K}$ s-orbitals (out of scale on these figures) which are not relevant for the present analysis. Figure $7 \mathrm{~b}$ shows the PDOS of the adsorbed methyl iodide molecule and the Mo and $\mathrm{C}$ surface atoms. Two peaks at -6.2 and $-4.2 \mathrm{eV}$ belong to the $\mathrm{CH}_{3}$ group and to the I atom from the adsorbed methyl iodide, respectively.

Kitchin et al. ${ }^{31}$ compared the electronic $d$ band structures of $\beta-\mathrm{Mo}_{2} \mathrm{C}(001)$ surfaces with those of $\mathrm{Mo}(110)$ and $\mathrm{Pt}(111)$ and also report similar bands that associate with hybridization between $\mathrm{d}$-orbitals and the carbon $\mathrm{s}-\mathrm{p}$ orbitals.

3.4. Methyl lodide Dissociation. We also studied the primary dissociation process of an adsorbed $\mathrm{CH}_{3} \mathrm{I}$ molecule yielding

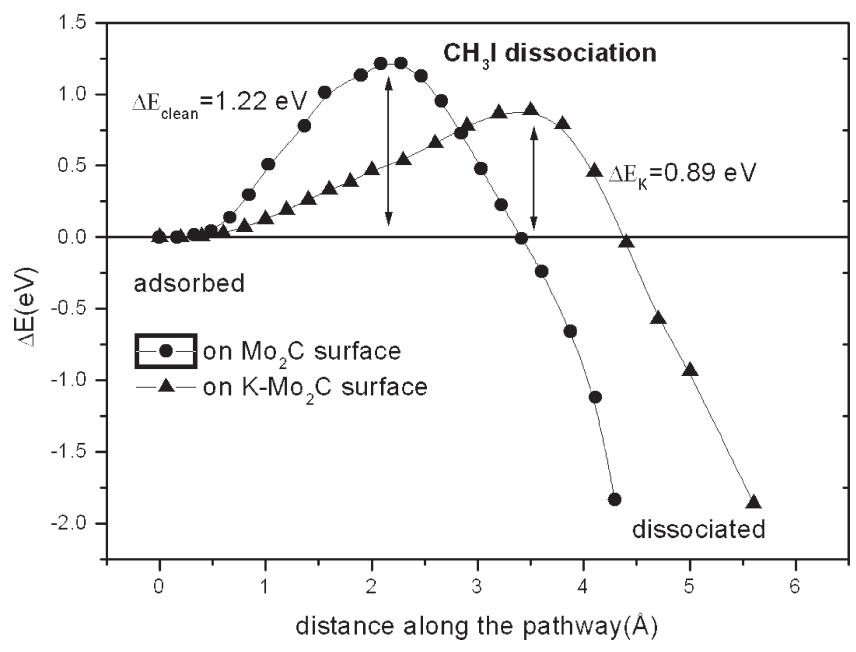

Figure 6. Energy changes along the reaction pathway for the clean and K-promoted $\mathrm{Mo}_{2} \mathrm{C}$ surface.
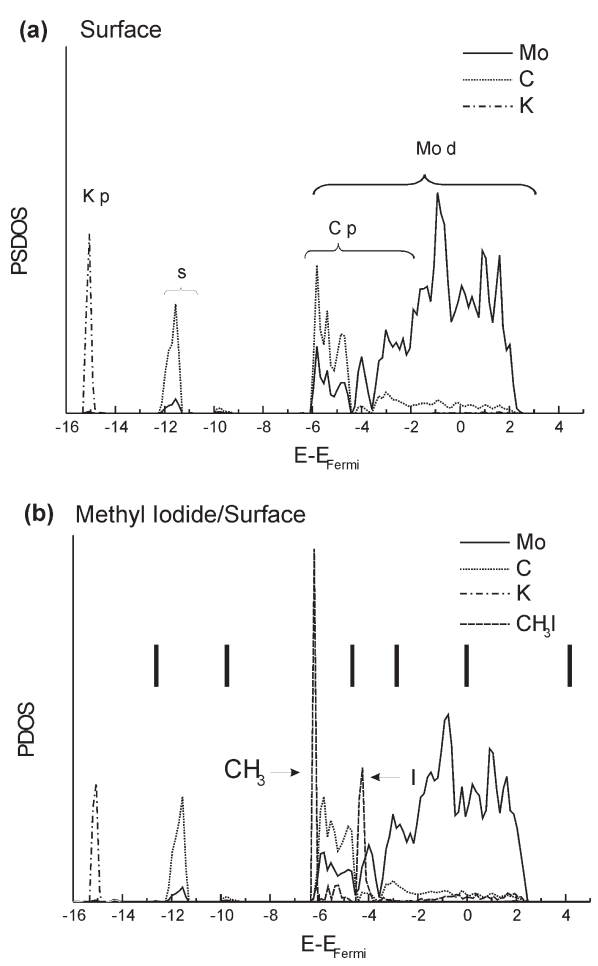

Figure 7. PDOS on Mo, C, and $\mathrm{K}$ surface atoms for Mo-terminated surface (a) PDOS on Mo, $\mathrm{C}$, and $\mathrm{K}$ surface atoms and the $\mathrm{CH}_{3} \mathrm{I}$ molecule, when $\mathrm{CH}_{3} \mathrm{I}$ is adsorbed on the surface (b). The marks represent molecular states of $\mathrm{CH}_{3} \mathrm{I}$ prior to adsorption.

adsorbed $\mathrm{CH}_{3}$ and $\mathrm{I}\left(\mathrm{CH}_{3} \mathrm{I}=\mathrm{CH}_{3(\mathrm{a})}+\mathrm{I}_{(\mathrm{a})}\right)$. The formation of $\mathrm{CH}_{3}$ fragments has been detected by HREEL spectroscopy on the $\mathrm{K}$-dosed $\mathrm{Mo}_{2} \mathrm{C}$ surface even at $100 \mathrm{~K}^{15}$

We investigated the dissociation process and the effect of $\mathrm{K}$ by first analyzing the stability of adsorbed species on the surface and then modeling a plausible reaction path. The preferential adsorption sites for the $\mathrm{CH}_{3}$ on a clean and $\mathrm{K}$-promoted $\mathrm{Mo}_{2} \mathrm{C}$ surface were found by placing the fragment at different positions on the surface and performing a full geometry optimization. The distances and $\mathrm{OP}$ values between the atoms of the different fragments and the surface are shown in Table 5. On the clean 
Table 5. Distances and OP Values between Atoms from Dissociated Species on Clean and Potassium Promoted Surfaces

\begin{tabular}{lccccc} 
& \multicolumn{2}{c}{ clean $\mathrm{Mo}_{2} \mathrm{C}$} & & \multicolumn{2}{c}{$\mathrm{K}-\mathrm{Mo}_{2} \mathrm{C}$} \\
\cline { 2 - 3 } \cline { 6 - 6 } \multicolumn{1}{c}{ species } & distance & OP & & distance & OP \\
C-Mo (avg) & 2.540 & 0.227 & & 2.367 & 0.262 \\
I-Mo2 & 2.850 & 0.388 & & 3.627 & 0.027 \\
I-Mo3 & 2.960 & 0.280 & & 4.080 & $\sim 0$ \\
I-Mo4 & 2.770 & 0.450 & & 2.920 & 0.430 \\
I-K & - & - & & 3.430 & 0.195 \\
\hline
\end{tabular}

Table 6. Electron Charges of Adsorbed and Dissociated Species on Clean and on K-Promoted Surface

\begin{tabular}{llcc} 
& species & clean $\mathrm{Mo}_{2} \mathrm{C}$ & $\mathrm{K}-\mathrm{Mo}_{2} \mathrm{C}$ \\
adsorbed & $\mathrm{CH}_{3} \mathrm{I}$ & -0.246 & -0.515 \\
dissociated & $\mathrm{CH}_{3}$ & -0.507 & -0.570 \\
& $\mathrm{I}$ & -0.405 & -0.606 \\
\hline
\end{tabular}

surface, the methyl group locates on a 3-fold site after dissociation at an average distance of $2.54 \AA$ from its Mo first neighbors, and the I atom, which remains on a 3-fold site, gets closer to the surface (with average I-Mo distances of $2.86 \AA$ ).

When dissociation occurs on the K-doped surface, the methyl group also adsorbs on a 3-fold Mo site with a rearrangement of the $\mathrm{K}$ and $\mathrm{I}$ atoms on the surface, keeping almost the same distance between each other of about $3.4 \AA$ (see Figure 5). This value is similar to the experimental value of the $\mathrm{K}-\mathrm{I}$ distance of $3.526 \AA$ for bulk fcc KI. ${ }^{46}$ Due to this rearrangement, I atom results almost on top of Mo4.

Figure 5 shows the suggested reaction path as the adsorbed molecule on a 3-fold site breaks its $\mathrm{C}-\mathrm{I}$ bond and the $\mathrm{CH}_{3}$ fragment locates on another 3-fold site. During this process, on the clean surface, the energy of the system decreases by $1.83 \mathrm{eV}$ with respect to energy of the molecular adsorbed state with an activation energy barrier of $1.21 \mathrm{eV}$. In the case of the K-promoted surface, we observed a similar decrease in the energy of the system, $1.86 \mathrm{eV}$, with a lower activation energy, $0.89 \mathrm{eV}$. Figure 6 shows the energy changes along the reaction pathway for the clean and K-promoted $\mathrm{Mo}_{2} \mathrm{C}$ surface. A reduction of $1.43 \mathrm{eV}$ was obtained under a similar dissociation path for $\mathrm{CH}_{3} \mathrm{I}$ on $\mathrm{Ni}(111)$ using the BOC-MP method. ${ }^{47}$

Table 6 shows the charges of adsorbed and dissociated species on both surfaces. On the clean surface, the dissociated $\mathrm{CH}_{3}$ and I have negative charges of $-0.507 \mathrm{e}^{-}$and $-0.405 \mathrm{e}^{-}$, respectively. As a whole, all the adsorbed species have a net charge of $-0.912 \mathrm{e}^{-}$. On the K-promoted surface, starting with a more negatively adsorbed $\mathrm{CH}_{3} \mathrm{I}$, the dissociated species have a larger amount of electron density. As a result, the net charge transfer to the species is $-1.177 \mathrm{e}^{-}$.

We can conclude that the promoter effect of potassium can be explained by the extended electron donation from the $\mathrm{K}-\mathrm{Mo}_{2} \mathrm{C}$ system to the adsorbed $\mathrm{CH}_{3} \mathrm{I}$ to form a partially negatively charged species that dissociates more easily. This conclusion is in agreement with Farkas et al. ${ }^{15}$

\section{CONCLUSIONS}

The adsorption of methyl iodide and the first step on its dissociation on a clean and $\mathrm{K}$-promoted $\beta-\mathrm{Mo}_{2} \mathrm{C}(001)$ surface were computed using DFT calculations. The methyl iodide adsorbs preferentially on 3-fold Mo sites on both surfaces, being more favorable on clean $\beta-\mathrm{Mo}_{2} \mathrm{C}(001)$.

In both cases, the molecule withdraws charge from the surface being the higher transfer from the K-promoted surface, which is also verified by work function measurements.

The $\mathrm{C}$-I distance increases when the molecule is adsorbed on the surface. The largest elongation occurs on the K-promoted surface, where the OP value between $\mathrm{C}$ and I atoms presents the largest decrease. This corresponds to a larger weakening of the $\mathrm{C}-\mathrm{I}$ bond.

The dissociation to an I adsorbed atom and a methyl group adsorbed is energetically favorable for both surfaces, but there is a lower activation barrier on the K-doped surface. Also, considering the changes in the bonding, in the case of methyl iodide the $\mathrm{C}-\mathrm{I}$ bond becomes weaker when the molecule adsorbs on the surface with potassium. These observations indicate that potassium promotes the cleavage of the $\mathrm{C}-\mathrm{I}$ bond. The promoter effect of potassium can be explained by the extended electron donation from the $\mathrm{K}-\mathrm{Mo}_{2} \mathrm{C}$ system to the adsorbed $\mathrm{CH}_{3} \mathrm{I}$ to form a partially negatively charged species that dissociates more easily.

\section{ACKNOWLEDGMENT}

The authors thank the SGCyT-UNS, CONICET-PIP 2009, ANPCyT (PICT 560 and PICTR 656), and MINCyT-Argentina/ NKTH-Hungary for their financial support. Support by Hungarian National Foundation, OTKA NI 69327 and K81660 is gratefully acknowledged. M. E. Pronsato, A. Juan, and C. Pistonesi are members of CONICET.

\section{REFERENCES}

(1) Wonchoba, S. E.; Truhlar, D. G. J. Phys. Chem. B 1998, 102, 6842-6860.

(2) Pascal, M.; Lamont, C. L. A.; Kittel, M.; Hoeft, J. T.; Constant, L.; Polcik, M.; Bradshaw, A. M.; Toomes, R. L.; Woodruff, D. P. Surf. Sci. 2002, 512, 173-184.

(3) Ciobica, I. M.; Frechard, F.; van Santen, R. A.; Kleyn, A. W.; Hafner, J. J. Phys. Chem. B 2000, 104, 3364-3369.

(4) Bent, B. E. Chem. Rev. 1996, 96, 1361-1390.

(5) Zhen, M.; Zaera, F. Surf. Sci. Rep. 2006, 61, 229-281.

(6) Gefei, Wu; Molero, H.; Tysoe, W. T. Surf. Sci. 1998, 397, 179184.

(7) Mezhenny, S.; Sorescu, D. C.; Maksymovych, P.; Yates, J. T. J. Am. Chem. Soc. 2002, 124, 14202-14209.

(8) Hwu, H. H.; Chen, J. G. Chem. Rev. 2005, 105, 185-212.

(9) Solymosi, F.; Erdohelyi, A.; Szoke, A. Catal. Lett. 1995, 32, $43-$ 53.

(10) Solymosi, F.; Bugyi, L.; Oszkó, A. Catal. Lett. 1999, 57, 103107.

(11) Tominaga, H.; Nagai, M. App. Catal. A: Gen. 2007, 328, 35-42.

(12) Bonzel, H. P. Surf. Sci. Rep. 1988, 8, 43-125.

(13) Bonzel, H. P., Bradshaw, A. M., Ertl, G., Eds. Physics and Chemistry of Alkali Metal Adsorption; Elsevier: Amsterdam, 1989.

(14) Chen, J. G. Chem. Rev. 1996, 96, 1477-1498.

(15) Farkas, A. P.; Koos, A.; Bugyi, L.; Solymosi, F. J. Phys. Chem. C 2008, 112, 18505-18509.

(16) Farkas, A. P.; Bugyi, L.; Koós, Á.; Solymosi, F. Surf. Sci. 2006, 600, 2355-2363.

(17) Farkas, A. P.; Bugyi, L.; Koós, Á.; Solymosi, F. Surf. Sci. 2007, 601, 3736-3739.

(18) Kiss, J.; Berkó, A.; Révész, K.; Solymosi, F. Surf. Sci. 1990, 240, $59-70$. 
(19) Kiss, J; Kis, A.; Solymosi, F. Surf. Sci. 2000, 454-456, 273-279.

(20) Solymosi, F. J. Mol. Catal. A 1998, 131, 121-133.

(21) Kresse, G.; Furthmüller, J. Phys. Rev. B 1996, 54, 11169-

11186. Kresse, G.; Furthmüller, J. Comput. Mater. Sci. 1996, 6, 15-50.

(22) Kresse, G.; Joubert, J. Phys. Rev. B 1999, 59, 1758-1755.

(23) Perdew, J. P.; Burke, K.; Ernzerhof, M. Phys. Rev. Lett. 1996, 77, $3865-3868$.

(24) Perdew, J. P.; Burke, K.; Ernzerhof, M. Phys. Rev. Lett. 1997, 78, 1396-1396.

(25) Press, W. H.; Flannery, B. P.; Teukolsky, S. A.; Vetterling, W. T. Numerical Recipies; Cambridge University Press: New York, 1986.

(26) Bader, R. F. W. Atoms in Molecules - A Quantum Theory; Oxford University Press: Oxford, 1990.

(27) Landrum, G.; Glassey, W. Yet Another Extended Hückel Molecular Orbital Package (YAeHMOP); Cornell University: New York, 1997. http://yaehmop.sourceforge.net.

(28) Papoian, G.; J. Norskov, J.; Hoffmann, R. J. Am. Chem. Soc. 2000, 122, 4129-4144.

(29) Parthé, E.; Sadagopan, V. Acta Crystallogr. 1963, 16, 202-205.

(30) Haines, J.; Léger, J.; Chateau, C.; Lowther, J. J. Phys.: Condens. Matter 2001, 13, 2447-2454.

(31) Kitchin, J. R.; Norskov, J. K.; Barteau, M. A.; Chen, J. G. Catal. Today 2005, 105, 66-73.

(32) Pistonesi, C.; Juan, A.; Farkas, A. P.; Solymosi, F. Surf. Sci. 2008, 60, 2206-2211.

(33) Pistonesi, C.; Juan, A.; Farkas, A. P.; Solymosi, F. Surf. Sci. 2010, 604, 914-919.

(34) Calzado, C. J.; San Miguel, M. A.; Sanz, J. F. J. Phys. Chem. B 1999, 103, 480-486.

(35) Mutombo, P.; Kees, A. M.; Berko, A; Chab, V. Nanotechnology 2006, 17, 4112-4116.

(36) Kotarba, A.; Adamski, G.; Piskorz, W.; Sojka, Z.; Sayag, C.; Djega-Mariadassou, G. J. Phys. Chem. B 2004, 108, 2885-2892.

(37) Zaera, F. Acc. Chem. Res. 1992, 25, 260-265.

(38) Ma, Z; Zaera, F. Surf. Sci. Rep. 2006, 61, 229-281.

(39) Solymosi, F.; Bugyi, L; Oszkó, A. Catal. Lett. 1999, 57, 103-107.

(40) Solymosi, F.; Bugyi, L; Oszkó, A.; Horváth, I. J. Catal. 1999, $185,160-169$.

(41) Bugyi, L.; Oszkó, A.; Solymosi, F. Surf. Sci. 2002, 516, 74-84.

(42) Bugyi, L.; Oszkó, A.; Solymosi, F. Surf. Sci. 2002, 519, 139-149.

(43) Bugyi, L.; Oszkó, A.; Solymosi, F. Surf. Sci. 2004, 561, 57-68.

(44) Bugyi, L.; Oszko, A. Surf. Sci. 2000, 461, 177-190.

(45) Yang, M. X.; Jo, S. K.; Paul, A.; Avila, L.; Bent, B. E.; Nishikida, K. Surf. Sci. 1995, 325, 102-120.

(46) Pathak, P. F.; Pandya, N. V. Indian J. Phys. 1960, 34, 416-423.

(47) Azizian, S.; Gobal, F. J. Mol. Catal. A: Chem. 2000, 153, 191197. 